\title{
AV ALIA ÇÃO DE CULTIV ARES DE SOJA (Glycine max (L.) MERRIL) EM COMPETIÇÃO COM Euphorbia heterophylla L. SOB TRÊS DENSIDADES E DOIS PERÍODOS DE OCORRÊNCIA
}

\author{
V. M. CHEMALE* \& N. G. FLECK** \\ * Bióloga - Instituto de Pesquisa Agronômica \\ (IPAGRO), Porto Alegre — RS, 90000. \\ ** Professor Adjunto - Depto. de Fitotecnia da \\ Faculdade de Agronomia da UFRGS - Porto \\ Alegre - RS, 90000. Bolsista do CNPq. \\ Parte da dissertação de mestrado em agrono - \\ mia do primeiro autor; Faculdade de Agro- \\ nomia/UFRGS. \\ Trabalho realizado com recursos financeiros \\ provenientes do CNPq, da EMBRAPA, da \\ FAPERGS e PROPESP/UFRGS.
}

\section{RESUMO}

O presente trabalho, conduzido durante o ano agrícola de 1979/80 na Estação Experimental Agronômica de UFRGS, em Guaíba, RS, apresentou como objetivo testar quatro cultivares de soja (Paraná, Prata, Hood e IAS-4) quanto à sua habilidade em concorrer com Euphorbia heterophylla L. (leiteira, amendoim-bravo) estabelecida em três densidades $\left(0,12\right.$ e 54 plan-tas $/ \mathrm{m}^{2}$, em média) e dois períodos de duração da competição (45 e 115 dias após a emergência da soja).

Constatou-se que houve redução no rendimento de grãos de soja por efeito dos dois periodos de competição e das densidades de E. heterophylla L. referidas. Também os números de grãos e de legumes por área foram consideravelmente reduzidos pela presença da planta daninha associada ao periodo mais prolongado de competição.

A espessura do caule e o número de nós das plantas de soja decresceram apenas sob o efeito da maior densidade da Euphorbia; entretanto, o número de ramos e o índice de área foliar, este aos 75 dias após a emergência da cultura, sofreram redução com a infestação de 12 plantas de Euphorbia por m2.

PALAVRAS CHAVE: Plantas daninhas, competição, Euphorbia heterophylla L., soja, cultivares.

\section{SUMMARY}

EVALUATION OF SOYBEAN (Glycine max (L.) Merrill) CULTIVARS IN COMPETITION WITH Euphorbia heterophylla L. IN THREE DENSITIES AND TWO PERIODS OF OCCURRENCE A field experiment was performed at the Agronomy Experimental Station of UFRGS, in Guaiba, RS, Brazil, during the 1979/80 growing

season, in order to test four soybean cultivars (Paraná, Prata, Hood e IAS-4) in competition with Euphorbia heterophylla L. established in three densities $\left(0,12\right.$ and 54 plants $\left./ \mathrm{m}^{2}\right)$ during two periods ( 45 and 115 days after soybean emergence).

It was observed that soybean cultivars presented reduction of seed yields under the effect of the periods of competition and densities of Euphorbia heterophylla $L$. The number of seeds and pods per area were considerably reduced in the presence of the weed associated with the longest competition period.

The stem diameter and number of nodes were reduced only by competition of the highest Euphorbia density; however, the number of branches and leaf area index, this after a period of 75 days of crop-weed association, were already reduced by a density of 12 plants $/ \mathrm{m}^{2}$ of Euphorbia heterophylla L.

KEYWORDS: Weeds, competition, Euphorbia heterophyllaL., soybean, cultivars.

\section{INTRODUÇÃO}

A competição com plantas daninhas é um dos fatores que mais afeta a produtividade da cultura da soja, podendo ocasionar redução de $90 \%$ em seu rendimento quando tais espécies não são consideradas $(2)$.

A competição por luz, água e nutrientes são os principais fatores ambientais pelos quais concorrem cultura e plantas daninhas. O poder de interceptação de luz pelas plantas daninhas é fator impor- 
tante da agressividade para as plantas cultivadas (4). A umidade adequada no início do ciclo da cultura favorece as maiores infestações de plantas daninhas, tornando-se fator limitante da produção quando ocorrer deficiência hídrica em estádios posteriores (19) .

A competição global se manifesta com a diminuição qualitativa e quantitativa do rendimento. O conhecimento do período crítico de competição determina a época conveniente para execução de práticas de controle, quer sejam mecânicas ou químicas.

Vários trabalhos têm demonstrado que à medida que se aumenta o período de competição, ocorre um incremento no efeito negativo das plantas daninhas sobre o rendimento da cultura $(1,7,11)$. Coble e Ritter (6) e Thurlow e Buchanan (18) concluíram que a soja pode suportar aproximadamente quatro semanas de competição com as plantas daninhas, na maioria das condições, sem sofrer redução no rendimento. Por outro lado, Pyon e Kim (16) determinaram que, mantendo-se a soja livre reservas daninhas por duas semanas, atingia-se alto nivel de rendimento. Também enfatizaram que a máxima redução do rendimento de grãos de soja foi obtida quando as plantas daninhas não foram controladas durante pouco mais de seis semanas. Nesse mesmo sentido, Hamerton (11) observou que, controlando as plantas daninhas durante seis semanas após a emergência da cultura, já se conseguia um rendimento de $85 \%$ do total que ela poderia produzir.

A capacidade competitiva dos cultivares varia de acordo com a espécie daninha com a qual estiver competindo (7 ). Burnside (3), testando a habilidade competitiva de dez cultivares de soja com

Amaranthus tuberculatus (Moq.) J. Sauer e Setaria viridis (L.) Beauv., concluiu que o cultivar Wayne apresentou melhor habilidade em competir com a planta daninha do que os outros nove cultivares ; enquanto 'Harosoy 63', 'Shelby' e 'Cor-soy' foram os cultivares que apresenta- ram melhor capacidade em competir com as plantas infestantes.

Segundo Nester et al. (15), Euphorbia heterophylla L. não é tão competitiva como Xanthium e Ipomoea quando considerada uma população de uma planta por metro de fileira. Entretanto, oito plantas de Euphorbia heterophylla L. por metro de fileira causaram perdas de 19,21 e $33 \%$ quando a competição se prolngou por 8 e 12 semanas e por todo o ciclo, respectivamente. Torna-se, portanto, importante conhecer como diferentes cultivares de soja reagem à competição de Euphorbia, bem como o grau de competição desta nas condições do Rio Grande do Sul, assim como a influência de sua concor rência em diferentes fases do ciclo da cultura.

\section{MATERIAIS E MÉTODOS}

Um experimento de competição entre cultivares de soja e Euphorbia heterophylla L. foi conduzido em condições de campo durante o ano agrícola de 1979/80, na Estação Experimental Agronômica da Universidade Federal do Rio Grande do Sul (EEA/UFRGS), situada na região fisiográfica da Depressão Central do Rio Grande do Sul. A pesquisa foi conduzida em solo pertencente à unidade de mapeamento Arroio dos Ratos, classificado como de textura franco-argiloso-arenosa, contendo $1,3 \%$ de matéria orgânica. As adubações de correção e de manutenção da área experimental foram efetuadas conforme recomendações provenientes da análise química do solo, executada pelo Laboratório de Análises de Solo da Faculdade de Agronomia da UFRGS.

A semeadura da soja foi realizada manualmente em 22 de novembro de 1979, tendo as sementes sido previamente inoculadas com Rhizobium japonicum (Kirchner.) Buchanan. As densidades de Euphorbia foram estabelecidas através de semeadura manual no dia precedente à semeadura da cultura.

Os tratamentos foram dispostos no delineamento experimental de parcelas subdivididas, dispostas em blocos casua- 
lizados, repetidos quatro vezes, resultando num total de 144 unidades experimentais. Cada unidade experimental foi constituída de quatro fileiras de plantas de soja com $5 \mathrm{~m}$ de comprimento, espaçadas de $0,5 \mathrm{~m}$. As duas fileiras laterais e $0,5 \mathrm{~m}$ nas extremidades de cada fileira central foram consideradas bordaduras, ficando a área útil composta pelas duas fileiras centrais com 4 metros de comprimento, resultando numa área de $4 \mathrm{~m}^{2}$ para as avaliações.

Para avaliar os efeitos iniciais da competição foram determinadas após 45, 60 e 75 dias da emergência da soja as estaturas de 15 plantas de soja por sub-subparcela. Aos 45 dias de crescimento foram coletadas seis plantas de cada cultivar de soja para determinação dos respectivos indices de área foliar. Também, nesta ocasião, foram removidas todas as plantas de Euphorbia correspondentes ao período inicial de competição. Aos 75 dias após a emergência da soja houve nova avaliação do índice de área foliar das plantas de soja.

A colheita da soja foi efetuada aos $128,136,134$ e 148 dias após a emergência da cultura, respectivamente, para os cultivares Prata, Paraná, Hood e IAS-4. Nesta ocasião foi avaliada a população final dos cultivares. Por ocasião da colheita da soja, foram retiradas 15 plantas da área útil de cada sub-subparcela. Em cada uma das plantas amostradas foram determinados os seguintes parâmetros : número de nós e número de ramificações no caule principal, estatura da planta, altura do ponto de inserção dos primeiros legumes, diâmetro do caule no segundo entre-nó do caule principal, número de legumes e de grãos por unidade de área $\left(\mathrm{m}^{2}\right)$, número de grãos/legume e peso do grão, calculando-se os valores médios por planta para cada um dos caracteres citados.

Para determinação do rendimento de grãos na área útil das sub-subparcelas, os grãos das plantas trilhadas foram pesados e determinada a umidade, sendo o peso de grãos corrigido para $13 \%$ de umidade.
A colheita de Euphorbia das parcelas correspondentes ao período mais longo de competição foi procedida aos 115 dias após a emergência da soja.

Os dados coletados foram submetidos à análise de variância e as médias dos tratamentos foram comparadas aplicando-se o teste de Duncan ao nível de $5 \%$ de probabilidade.

Foi realizada a análise de regressão entre rendimento de grãos da cultura e densidade da espécie daninha para períodos de competição e individualizada para os quatro cultivares de soja, tendo sido testados os modelos linear e quadrático de equações de regressão.

\section{RESULTADOS E DISCUSSÃO}

Constatou-se, pela análise da variância que, para rendimento de grãos de soja, houve significância estatística para as interações de densidade com períodos de competição e de densidades com cultivares (Quadros 1 e 2 ). Considerando o período de competição de 45 dias, houve redução no rendimento de grãos dos cultivares de soja, somente com a máxima infestação da espécie daninha (Quadro 1). No entanto, para o período de competição de 115 dias, a menor densidade de Euphorbia (12 plantas por $\mathrm{m}^{2}$ ) já causou redução no rendimento de grãos. Essa redução foi mais severa quando se elevou a densidade de Euphorbia de 12 para 54 plantas por $\mathrm{m}^{2}$ (Quadro 1). Através desses resultados, verificou-se que o período de competição de 115 dias afetou de forma mais severa o rendimento de grãos do que o período de 45 dias, desde que para o período de 45 dias houve redução de rendimento apenas sob a densidade maior de Euphorbia. Segundo vários autores $(2,11,16)$, o período de 45 dias se situa dentro daquele em que a competição é crítica para a cultura da soja. Nesse mesmo sentido, Barrentine (1), Coble e Ritter (6) e Thurlow e Buchanan (18) detectaram que o periodo crítico de competição entre espécies daninhas e soja se enquadrava dentro das quatro semanas de associação cultura/ espécie daninha. 


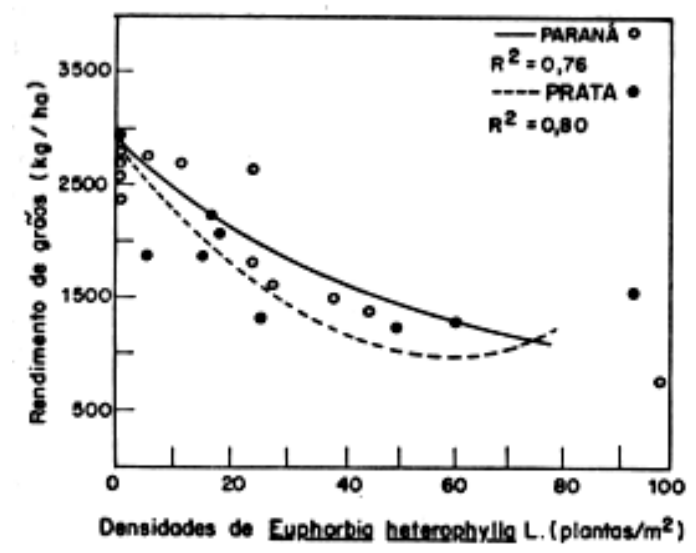

FIGURA I . Efeito de 115 dias de competicão de Euphorbia heterophyllo L. sobre o rendimento de grãos dos cultivares de soja de ciclo precoce (Paraná e Prato ), EEA /UFRGS , Guaíbo, RS, 1979/80

Os cultivares Paraná e IAS-4 apresentaram um comportamento semelhante para o efeito da competição com as infestações de Euphorbia sobre o rendimento de grãos (Quadro 2). Esses cultivares não sofreram redução no rendimento de grãos com a menor densidade de Euphorbia (12 plantas $\left./ \mathrm{m}^{2}\right)$. No entanto, com densidade de Euphorbia de 54 plantas por $\mathrm{m}^{2}$ ambas as variedades tiveram seus rendimentos de grãos reduzidos. Os cultivares Prata e Hood já apresentaram redução no rendimento de grãos por efeito da competição para 12 plantas de Euphorbia por $\mathrm{m}^{2}$. Quando a densidade de Euphorbia aumentou para 54 plantas por $\mathrm{m}^{2}$, a redução no rendimento desses cultivares também se elevou.

Os componentes do rendimento mais afetados pela competição foram o núme ro de legumes por $\mathrm{m}^{2}$ e o número de grãos por $\mathrm{m}^{2}$ (Quadros 3 e 4). Verificouse um efeito significativo para interação de períodos de competição com densidades. Para o período de 45 dias, não houve efeito das densidades de Euphorbia sobre esses componentes. Porém, para o período de competição maior (115 dias), à medida que aumentou a densidade de Euphorbia, houve uma maior redução no número de legumes e de grãos por $\mathrm{m} 2$. Vários autores $(3,7,10,12,13)$, encon- traram que os componentes do rendimento que sofreram maior efeito da competição foram o número de legumes e o número de grãos por planta. Por outro lado, grãos por legume e o peso do grão não sofreram oscilação por efeito da competição. Da mesma maneira Staniforth (17) não detectou redução no nú mero de grãos por legume e no peso do grão devido à competição no trabalho que conduziu. Verificou-se que os cultivares que apresentaram maiores rendimentos de grãos (Paraná e IAS-4) também apresentaram maior população de plantas e maior número de legumes por $\mathrm{m} 2$ (Quadro 5), concluindo-se que a diferença encontrada entre cultivares quanto a esses componentes foram as principais determinantes na diferença obtida entre o rendimento de grãos desses cultivares.

Três fatores podem ter contribuído para uma maior habilidade competitiva demonstrada pelos cultivares Paraná e IAS-4. No cultivar Paraná, a maior população de plantas (Quadro 5) deve ter proporcionado melhores condições para resistir à competição. Por outro lado, verific ou-se que o cultivar IAS-4, ape sar de não ter dife rido estatisticamente do Prata, apresentou maior população de plantas que o Hood. No momento em que um determinado cultivar de soja apresentar

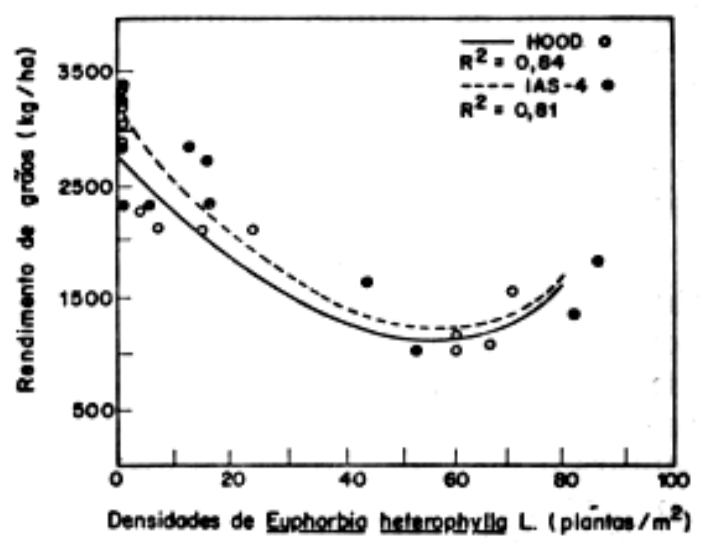

FIGURA 2. Efeito de 115 dias de competição de Euphorbia heterophylla L. sobre o rendimento de grãos dos cultivares de soja de ciclo médio (Hood e IAS-4), EEA/UFRGS,Guaíbo,RS, 1979/80. 
um crescimento rápido e vigoroso determinará uma limitação de luz, reduzindo a agressividade das plantas daninhas, sobrepujando-as (14).

Quanto aos outros caracteres agronômicos, verificou-se que a espessura do caule e o número de nós nos cultivares foram reduzidos sob o efeito competitivo da densidade de 54 plantas de Euphorbia por $\mathrm{m}^{2}$, não sendo afetadas pela densidade de 12 plantas por $\mathrm{m}^{2}$ (Quadro 6). 0 número de ramos já sofreu redução com a infestação de 12 plantas por $\mathrm{m}^{2}$, sendo que essa redução aumentou quando a densidade de Euphorbia foi de 54 plantas por $\mathrm{m}^{2}$. Por outro lado, a estatura e o ponto de inserção dos primeiros legumes não foram atingidos pela competição (Quadro 6 ). Possivelmente os cultivares, por serem de ciclo precoce e médio, podem ter apresentado crescimento inicial rápido e no momento que atuou a competição os mesmos já teriam atingido a estatura máxima (Quadro 7 ) . Além da população de plantas, o segundo fator que pode ter influenciado a resposta diferenciada dos cultivares foi a estatura da planta. Os cultivares Paraná e IAS-4 apresentaram maior estatura do que os demais (Quadro 7). Esta estatura, possivelmente, esteja ligada a uma rápida germinação - emergência e crescimento inicial da planta de soja, que conferiu a esses cultivares maior capacidade competitiva com as plantas daninhas. Nesse sentido, Cartter e Hartwig (5) sugeriram que a planta de soja deve apresentar um vigoroso crescimento inicial, caracteristica esta determinada grandemente pela carga genética do cultivar.

$O$ terceiro fator que parece ter influenciado de maneira significativa no comportamento dos cultivares foi o in dice de área foliar aos 75 dias. Verificou se que os cultivares Paraná e IAS-4 apresentaram maiores indices de área foliar do que os outros dois, não diferindo en tre si (Quadro 8). Quanto à estatura de planta estes dois cultivares se destacaram dos demais apresentando maior estatura nos períodos em que foram medidos (Quadro 9).
Da mesma maneira, o ponto de inserção dos primeiros legumes já deveria estar formado quando iniciou a competição, fazendo com que esse caráter não tivesse sofrido efeito da competição. Também Fleck (9) observou reduções no número de ramos, espessura do caule e número de nós devido à competição de Cassia obtusifolia L. com soja. Esse mesmo autor não detectou efeito competitivo de C. obtusifolia L. na estatura da soja.

Os cultivares apresentaram diferenças quanto aos caracteres agronômicos avaliados ( Quadro 7 ). Atribuiu -se este fato às características genéticas de cada cultivar e ao ciclo dos mesmos. Talvez, também a população de plantas possa ter influenciado neste tipo de resposta, pois o cultivar Paraná se destacou apresentando maior população de plantas e o menor número de ramos ; enquanto os demais compensaram a menor população de plantas formando maior número de ramos ( Quadro 7 ).

Quanto ao indice de área foliar, observou-se que houve efeito competitivo para o período de 45 dias somente com a máxima infestação da espécie daninha. Quando foi prolongado o período da concorrência erva-cultura houve efeito da competição com a densidade de 12 plantas por $\mathrm{m}^{2}$. Á medida que aumentou a densidade de plantas de Euphorbia houve redução no índice de área foliar com 75 dias de competição (Quadro 10 ).

A análise de regressão entre densidades de Euphorbia e rendimento de grãos foram melhor expressas pelo modelo quadrático do que pelo linear (Quadro 11, Figuras 1 e 2). Esse fato deveu-se, provavelmente, à competição entre as próprias plantas daninhas, isto é, quando se aumentou a população das mesmas, começou uma severa competição intraespeci fica, somando-se ao efeito da concorrência com os cultivares de soja.

\section{LITERATURA CITADA}

1. Barrentine, W.L. Common cocklebur com petition in soybeans. Weed Science, 22: 600-603, 1974.

2. Blanco, H.G.; Oliveira, D.A.; Araújo, J.B.M. 
\& Grasi, N. Observações sobre o período em que as plantas daninhas competem com a soja (Glycine max (L.) Merrill). O Biológico, 39: 31-35, 1973.

3. Burnside, O.C. \& Colville, W.L. Soybean and weed yields as affected by irrigation, row spacing, tillage, and amiben. Weeds, 12: 109-112, 1964.

4. Camargo, P.N. Controle quimico de plantas daninhas. 2. ed., Piracicaba, ESALQ, 13,14, 1970.

6. Cartter, G.L. \& Hartwig, E.E. The manage ment of soybeans. In: Norman, A.E. The soybeans: genetics, breeding, physiology, nutrition, management. 2. ed. New York, Academic Press. p. 162-226, 1963.

7. Coble, H.D. \& Ritter, R.L. Pennsylvania smartweed (Polygonum pensylvanicum

L.) interference in soybeans (Glycine max

(L.) Merrill). Weed Science, 26: 556-559, 1978.

8. Eaton, B.J.; Feltner, K.C. \& Russ, O.G. Venice mallow competition in soybeans. Weed Science, 21: 89-93, 1973.

9. Eaton, B.J.; Russ, O.G. \& Feltner, K.C. Competition of velvetleaf, prickly sida, and Venice mallow in soybeans. Weed Science, 24: 224-228, 1976

10. Fleck, N.G. Competition of sicklepod, Cassia obtusifolia L., densities on soybean, Gly cine max (L.) Merril at variable row dis tances. 169f. Thesis (Ph.D.). University of Florida, 1976.

11. Hagood, E.S.; Bauman Jr., T.T.; Williams, G.L. \& Schreiber, M.M. Growth analysis of soybean (Glycine max (L.) Merrill) in competition with velvetleaf (Abutilon theophrasti Medic.). Weed Science, 28: 729-734, 1980.

13. Hamerton, J.L. Effects of weed competition, defoliation and time of harvest on soybeans. Experimental Agriculture, 8: 333-338, 1972.

14. Knake, E.L. \& Slife, F.W. Competition of Setaria faberii with corn and soybeans. Weeds, 10: 26-29, 1962.

15. Moolani, M.K.; Knake, E.L. \& Slife, F.W. Competition of smooth pigweed with corn and soybeans. Weeds, 12: 126-128, 1964.

16. Murphy, T.R. \& Gosset, B.J. Influence of shading by soybeans (Glycine max (L.) Merrill) on weed suppression. Weed Science, 29:610-615, 1981.

17. Nester, R.P.R.; Hargert, T.R. \& McCormic, L.L. Weed watch; wild poinsettia. Weeds Today, 10: 2425, 1979.

18. Pyon, G.Y. \& Kim, Y.R. Competitive effects of annual weeds on soybeans. Journal of Korean Society of Crop Science, 3: 86-89, 1978.

19. Staniforth, D.W. Soybean -foxtali competi tion under varying soil moisture condi tions. Agronomy Journal, 50: 13-15, 1958.

20. Thurlow, D.L. \& Buchanan, G.A. Competi tion of sicklepod with soybeans. Weed Science, 20:379-384, 1972.

21. Weber, C.R. \& Staniforth, D.W. Competition relationships in variable weed and soy bean stands. Agronomy Journal, 49: $440444,1957$.

QUADRO 1. Efeitos de três densidades de Euphorbia heterophylla L., em dois períodos de competição sobre o rendimento de grãos, em $\mathrm{kg} / \mathrm{ha}$, médias de quatro cultivares de soja, EEA/UFRGS, Guaíba, RS, 1979/80.

\begin{tabular}{|c|c|c|c|c|}
\hline \multirow{3}{*}{ Periodo de competição } & \multicolumn{4}{|c|}{ Densidades médias de Euphorbia heterophylla L. } \\
\hline & \multicolumn{4}{|c|}{ plantas $/ \mathrm{m}^{2}$} \\
\hline & $0(1)$ & 12 & 54 & Médias \\
\hline $\begin{array}{l}45 \operatorname{dias}^{(2)} \\
115 \text { dias }\end{array}$ & $\begin{array}{l}\text { a } 2865 \\
\text { a } 2966\end{array}$ & $\begin{array}{r}\text { ab } 2685 \text { a } \\
\text { b } 2313 \quad \text { b }\end{array}$ & $\begin{array}{l}\text { b } 2395 \text { a } \\
\text { c } 1471 \text { b }\end{array}$ & $\begin{array}{l}2648 \\
2250\end{array}$ \\
\hline médias & 2915 & 2499 & 1933 & 2449 \\
\hline
\end{tabular}

Médias comparadas no sentido horizontal, antecedidas da mesma letra, e médias comparadas no sentido vertical, seguidas da mesma letra, nāo diferem significativamente ao nível de $5 \%$ de probabilidade de acordo com o teste de Duncan.

(1) Ausência de plantas de $E$. heterophylla L. corresponde aos tratamentos testemunhas para comparação entre as densidades desta espécie dentro de cada período de competição.

(2) Após a emergência da soja. 
QUADRO 2. Efeitos de três densidades de Euphorbia heterophylla L., sobre o rendimento de grãos, em $\mathrm{kg} / \mathrm{ha}$, de quatro cultivares de soja, médias de dois períodos de competição, EEA/UFRGS, Guaíba, RS, 1979/80.

\begin{tabular}{|c|c|c|c|c|c|}
\hline \multirow{3}{*}{ (N) } & \multirow{3}{*}{ Cultivares de Soja } & \multicolumn{4}{|c|}{ Densidades médias de Euphorbia heterophylla $\mathrm{L}$. } \\
\hline & & \multicolumn{4}{|c|}{ plantas $/ \mathrm{m}^{2}$} \\
\hline & & \multicolumn{2}{|r|}{12} & 54 & \multirow{2}{*}{$\begin{array}{c}\text { Médias } \\
2398 \\
2291 \\
2469 \\
2639\end{array}$} \\
\hline 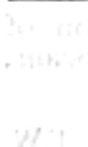 & $\begin{array}{l}\text { Paraná } \\
\text { Prata } \\
\text { Hood } \\
\text { IAS-4 }\end{array}$ & $\begin{array}{l}\text { a } 2689 \text { b } \\
\text { a } 2937 \text { a } \\
\text { a } 2974 \text { a } \\
\text { a } 3062 \text { a }\end{array}$ & 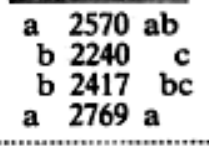 & $\begin{array}{l}\text { b } 1935 \text { ab } \\
\text { c } 1696 \text { b } \\
\text { c } 2015 \text { a } \\
\text { b } 2087 \text { a }\end{array}$ & \\
\hline 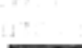 & Médias & 2915 & 2499 & 1933 & 2449 \\
\hline
\end{tabular}

Médias comparadas no sentido horizontal, antecedidas da mesma letra, e médias comparadas no sentido vertical, seguidas da mesma letra, näo diferem significativamente ao nível de $5 \%$ de probabilidade de acordo com o teste de Duncan.

QUADRO 3. Efeitos de três densidades de Euphorbia heterophylla L., em dois periodos de competição, sobre número de legumes por $\mathrm{m}^{2}$, médias de quatro cultivares de soja, EEA/ UFRGS, Guaíba, RS, 1979/80.

\begin{tabular}{|c|c|c|c|c|}
\hline \multirow{3}{*}{ Periodo de competição } & \multicolumn{4}{|c|}{ Densidades médias de Euphorbia heterophylla $\mathrm{L}$. } \\
\hline & \multicolumn{4}{|c|}{ plantas $/ \mathrm{m}^{2}$} \\
\hline & $0(1)$ & 12 & 54 & Médias \\
\hline $\begin{array}{l}45 \text { dias(2) } \\
115 \text { dias }\end{array}$ & $\begin{array}{l}\text { a } 1006 \\
\text { a } 1120\end{array}$ & a $\quad 987 a^{a}$ & $\begin{array}{l}\text { a } 928 \mathrm{a} \\
\text { c } 595 \mathrm{~b}\end{array}$ & $\begin{array}{l}974 \\
833\end{array}$ \\
\hline Médias & 1063 & 886 & 761 & 903 \\
\hline
\end{tabular}

Médias comparadas no sentido horizontal, antecedidas da mesma letra, e médias comparadas no sentido vertical, seguidas da mesma letra, não diferem significativamente ao nível de $5 \%$ de probabilidade de acordo com o teste de Duncan.

(1) Ausência de plantas de $E$. heterophylla L. corresponde aos tratamentos testemunhas para comparação entre as densidades desta espécie dentro de cada período de competição.

(2) Adós a emerzência da soia.

QUADRO 4. Efeitos de três densidades de Euphorbia heterophylla L., em dois períodos de competição, sobre número de grãos por $\mathrm{m}^{2}$, médias de quatro cultivares de soja, EEA/UFRGS, Guaíba, RS, 1979/80.

\begin{tabular}{|c|c|c|c|c|}
\hline \multirow{3}{*}{ Período de competiçăo } & \multicolumn{4}{|c|}{ Densidades médias de Euphorbia heterophylla L. } \\
\hline & \multicolumn{4}{|c|}{ plantas $/ \mathrm{m}^{2}$} \\
\hline & $0(1)$ & 12 & 54 & Médias \\
\hline $\begin{array}{c}45 \text { dias(2) } \\
115 \text { dias }\end{array}$ & $\begin{array}{l}\text { a } 1712 \\
\text { a } 1920\end{array}$ & 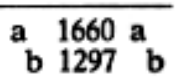 & $\begin{array}{l}\text { a } 1583 \text { a } \\
\text { c } 923{ }_{b}\end{array}$ & $\begin{array}{l}1652 \\
1380\end{array}$ \\
\hline Médias & 1816 & 1478 & 1253 & 1516 \\
\hline
\end{tabular}

Médias comparadas no sentido horizontal, antecedidas da mesma letra, e médias comparadas no sentido vertical, seguidas da mesma letra, não diferem significativamente ao nivel de $5 \%$ de probabilidade de acordo com o teste de Duncan.

(1) Ausência de plantas de $E$. heterophylla $\mathrm{L}$. corresponde aos tratamentos testemunhas para comparaçăo eritre as densidades desta espécie dentro de cada período de competição.

(2) Após a emergência da soja. 
QUADRO 2. Efeitos de três densidades de Euphorbia heterophylla L., sobre o rendimento de grãos, em $\mathrm{kg} / \mathrm{ha}$, de quatro cultivares de soja, médias de dois períodos de competição, EEA/UFRGS, Guaíba, RS, 1979/80.

\begin{tabular}{|c|c|c|c|c|c|}
\hline \multirow{3}{*}{ 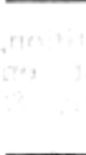 } & \multirow{3}{*}{ Cultivares de Soja } & \multicolumn{4}{|c|}{ Densidades médias de Euphorbia heterophylla $\mathrm{L}$. } \\
\hline & & \multicolumn{4}{|c|}{ plantas $/ \mathrm{m}^{2}$} \\
\hline & & $\mathbf{0}$ & 12 & 54 & \multirow{2}{*}{$\begin{array}{c}\text { Médias } \\
2398 \\
2291 \\
2469 \\
2639\end{array}$} \\
\hline 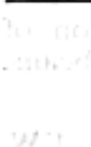 & $\begin{array}{l}\text { Paraná } \\
\text { Prata } \\
\text { Hood } \\
\text { IAS-4 }\end{array}$ & $\begin{array}{l}\text { a } 2689 \text { b } \\
\text { a } 2937 \text { a } \\
\text { a } 2974 \text { a } \\
\text { a } 3062 \text { a }\end{array}$ & $\begin{array}{l}\text { a } 2570 \text { ab } \\
\text { b } 2240 \text { c } \\
\text { b } 2417 \text { bc } \\
\text { a } 2769 a\end{array}$ & $\begin{array}{l}\text { b } 1935 \text { ab } \\
\text { c } 1696 \text { b } \\
\text { c } 2015 \text { a } \\
\text { b } 2087 \text { a }\end{array}$ & \\
\hline & Médias & 2915 & 2499 & 1933 & 2449 \\
\hline
\end{tabular}

Médias comparadas no sentido horizontal, antecedidas da mesma letra, e médias comparadas no sentido vertical, seguidas da mesma letra, não diferem significativamente ao nivel de $5 \%$ de probabilidade de acordo com o teste de Duncan.

QUADRO 3. Efeitos de três densidades de Euphorbia heterophylla L., em dois períodos de compe-tição, sobre número de legumes por $\mathrm{m}^{2}$, médias de quatro cultivares de soja, EEA/ UFRGS, Guaíba, RS, 1979/80.

\begin{tabular}{|c|c|c|c|c|}
\hline \multirow{3}{*}{ Período de competição } & \multicolumn{4}{|c|}{ Densidades médias de Euphorbia heterophylla $\mathrm{L}$. } \\
\hline & \multicolumn{4}{|c|}{ plantas $/ \mathbf{m}^{2}$} \\
\hline & $0(1)$ & 12 & 54 & Médias \\
\hline $\begin{array}{l}45 \text { dias(2) } \\
115 \text { dias }\end{array}$ & $\begin{array}{l}\text { a } 1006 \\
\text { a } 1120\end{array}$ & a 987 a & $\begin{array}{l}\text { a } 928 \text { a } \\
\text { c } 595 \text { b }\end{array}$ & $\begin{array}{l}974 \\
833\end{array}$ \\
\hline Médias & 1063 & 886 & 761 & 903 \\
\hline
\end{tabular}

Médias comparadas no sentido horizontal, antecedidas da mesma letra, e médias comparadas no sentido vertical, seguidas da mesma letra, não diferem significativamente ao nivel de $5 \%$ de probabilidade de acordo com o teste de Duncan.

(1) Ausência de plantas de $E$. heterophylla $L$. corresponde aos tratamentos testemunhas para comparação entre as densidades desta espécie dentro de cada período de competição.

(2) Após a emergência da soja.

QUADRO 4. Efeitos de três densidades de Euphorbia heterophylla L., em dois períodos de competição, sobre número de grãos por $\mathrm{m}^{2}$, médias de quatro cultivares de soja, EEA/UFRGS, Guaíba, RS, 1979/80.

\begin{tabular}{|c|c|c|c|c|}
\hline \multirow{3}{*}{ Período de competição } & \multicolumn{4}{|c|}{ Densidades médias de Euphorbia heterophylla $\mathrm{L}$. } \\
\hline & \multicolumn{4}{|c|}{ plantas $/ \mathrm{m}^{2}$} \\
\hline & $0(1)$ & 12 & 54 & Médias \\
\hline $\begin{array}{l}45 \text { dias(2) } \\
115 \text { dias }\end{array}$ & $\begin{array}{l}\text { a } 1712 \\
\text { a } 1920\end{array}$ & $\begin{array}{ll}\text { a } & 1660 \text { a } \\
\text { b } & 1297 \\
\text { b }\end{array}$ & a $1583 \quad a \quad 923 \quad b$ & $\begin{array}{l}1652 \\
1380\end{array}$ \\
\hline Médias & 1816 & 1478 & 1253 & 1516 \\
\hline
\end{tabular}

Médias comparadas no sentido horizontal, antecedidas da mesma letra, e médias comparadas no sentido vertical, seguidas da mesma letra, não diferem significativamente ao nível de $5 \%$ de probabilidade de acordo com o teste de Duncan.

(1) Ausência de plantas de $\boldsymbol{E}$. heterophylla $\mathrm{L}$. corresponde aos tratamentos testemunhas para comparaçäo eritre as densidades desta espécie dentro de cada período de competição.

(2) Após a emergência da soja. 
QUADRO 5. Componentes do rendimento de quatro cultivares de soja submetidos à competição de três densidades e dois períodos de ocorrência de Euphorbia heterophylla L., EE A/ UFRGS, Guaíba, RS, 1979/80.

\begin{tabular}{|c|c|c|c|c|}
\hline $\begin{array}{l}\text { Cultivares } \\
\text { de soja }\end{array}$ & $\begin{array}{l}\text { População de plantas } \\
\text { (plantas } / \mathrm{m}^{2} \text { ) }\end{array}$ & $\begin{array}{l}\text { Número de } \\
\text { legumes } / \mathrm{m}^{2}\end{array}$ & $\begin{array}{l}\text { Número de } \\
\text { grāos } / \mathrm{m}^{2}\end{array}$ & Grãos/legume \\
\hline $\begin{array}{l}\text { Paraná } \\
\text { Prata } \\
\text { Hood } \\
\text { IAS-4 }\end{array}$ & $\begin{array}{ll}21 & a \\
16 & b \\
14 & c \\
17 & b\end{array}$ & $\begin{array}{c}962 \text { a } \\
854 \quad \text { b } \\
739 \quad c \\
1059 \text { a }\end{array}$ & $\begin{array}{l}1525 \mathrm{~b} \\
1416 \mathrm{~b} \\
1383 \mathrm{~b} \\
1740 \mathrm{a}\end{array}$ & $\begin{array}{l}1,55 \mathrm{~b} \\
1,65 \mathrm{ab} \\
1,71 \mathrm{a} \\
1,61 \mathrm{ab}\end{array}$ \\
\hline Médias & 17 & 903 & 1516 & 1,63 \\
\hline
\end{tabular}

Médias comparadas no sentido horizontal, antecedidas da mesma letra, e médias comparadas no sentido vertical, seguidas da mesma letra, não diferem significativamente ao nível de $5 \%$ de probabilidade de acordo com o teste de Duncan.

QUADRO 6. Caracteres agronômicos, médias de quatro cultivares de soja sub metidos à compe tição de três densidades e dois períodos de ocorrência de Euphorbia heterophylla L., EEA/ UFRGS, Guaíba, RS, 1979/80.

\begin{tabular}{|c|c|c|c|c|c|}
\hline $\begin{array}{l}\text { Densidades médias de } \\
\text { E. heterophylla } \mathrm{L} \text {. } \\
\text { (plantas } / \mathrm{m}^{2} \text { ) }\end{array}$ & $\begin{array}{c}\text { Espessura do } \\
\text { caule (mm) }\end{array}$ & $\begin{array}{l}\text { Número } \\
\text { de nós }\end{array}$ & $\begin{array}{l}\text { Número } \\
\text { de ramos }\end{array}$ & $\begin{array}{l}\text { Estatura da } \\
\text { planta }(\mathrm{cm})\end{array}$ & $\begin{array}{l}\text { Ponto de inserção } \\
\text { dos primeiros } \\
\text { legumes }(\mathrm{cm})\end{array}$ \\
\hline $\begin{array}{r}0 \\
12 \\
54\end{array}$ & $\begin{array}{l}8,06 \mathrm{a} \\
7,65 \mathrm{ab} \\
7,37 \text { b }\end{array}$ & $\begin{array}{l}13,96 \text { a } \\
14,01 \text { a } \\
13,60 \text { b }\end{array}$ & $\begin{array}{l}5,2 \text { a } \\
4,5 \quad \text { b } \\
4,0 \quad \text { c }\end{array}$ & $\begin{array}{l}55,3 \\
55,0 \\
53,2\end{array}$ & $\begin{array}{l}11,6 \\
11,8 \\
11,3\end{array}$ \\
\hline Médias & 7,69 & 13,85 & 4,6 & 54,5 & 11,6 \\
\hline
\end{tabular}

Médias comparadas no sentido horizontal, antecedidas da mesma letra, e médias comparadas no sentido vertical, seguidas da mesma letra, não diferem significativamente ao nivel de $5 \%$ de probabilidade de acordo com o teste de Duncan.

QUADRO 7. Caracteres agronômicos de quatro cultivares de soja submetidos à competição de três densidades e dois períodos de ocorrência de Euphorbia heterophylla L., EEA/ UFRGS, Guaíba, RS, 1979/80.

\begin{tabular}{|c|c|c|c|c|c|}
\hline Cultivare de soja & $\begin{array}{c}\text { Espessura do } \\
\text { caule }(\mathrm{mm})\end{array}$ & $\begin{array}{l}\text { Número } \\
\text { de nós }\end{array}$ & $\begin{array}{l}\text { Número } \\
\text { de ramos }\end{array}$ & $\begin{array}{l}\text { Estatura da } \\
\text { planta }(\mathrm{cm})\end{array}$ & $\begin{array}{c}\text { Ponto de inserção } \\
\text { dos primeiros } \\
\text { legumes }(\mathrm{cm})\end{array}$ \\
\hline $\begin{array}{l}\text { Paraná } \\
\text { Prata } \\
\text { Hood } \\
\text { IAS-4 }\end{array}$ & $\begin{array}{l}7,2 \mathrm{~b} \\
7,4 \mathrm{~b} \\
8,2 \mathrm{a} \\
8,0 \mathrm{a}\end{array}$ & $\begin{array}{l}14,52 \text { a } \\
12,96 \text { b } \\
14,0 \text { a } \\
14,1 \text { a }\end{array}$ & $\begin{array}{l}3,8 \text { b } \\
4,9 \mathrm{a} \\
4,9 \mathrm{a} \\
4,8 \mathrm{a}\end{array}$ & $\begin{array}{l}59,5 \text { a } \\
46,8 \text { c } \\
50,3 \text { b } \\
61,6 \text { a }\end{array}$ & $\begin{array}{l}12,1 \text { ab } \\
10,1 \quad \mathrm{c} \\
11,0 \text { bc } \\
13,1 \mathrm{a}\end{array}$ \\
\hline Médias & 7,7 & 14,0 & 4,6 & 54,5 & 11,6 \\
\hline
\end{tabular}

Médias comparadas no sentido horizontal, antecedidas da mesma letra, e médias comparadas no sentido vertical, seguidas da mesma letra, nāo diferem significativamente ao nivel de $5 \%$ de probabilidade de acordo com o teste de Duncan. 
QUADRO 8. Indices de área foliar de quatro cultivares de soja submetidos à competição de três densidades e de dois períodos de ocorrência de Euphorbia heterophylla L., EEA/UFRGS, Guaíba, RS, 1979/80.

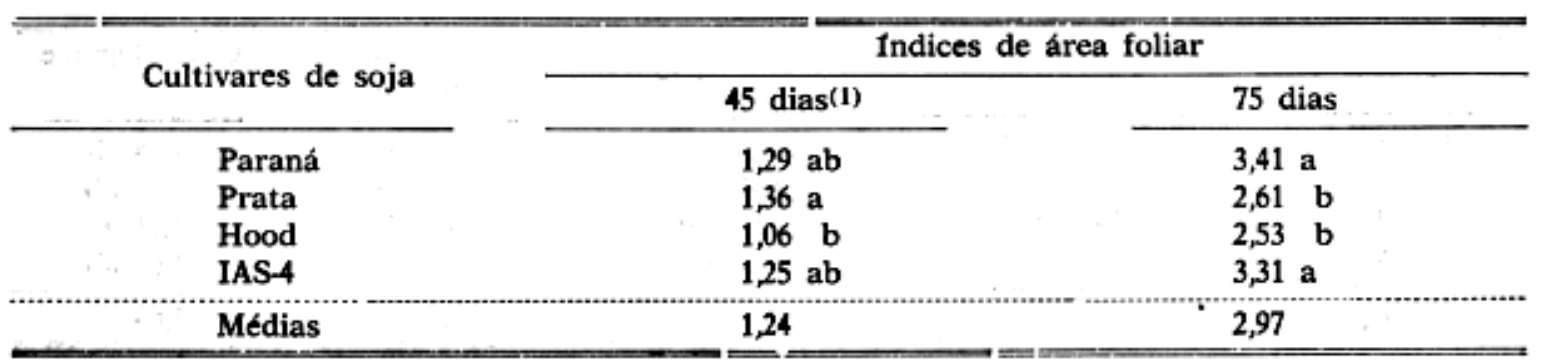

Médias comparadas no sentido horizontal, antecedidas da mesmà letra, e médias comparadas no sentido vertical, seguidas da mesma letra, nāo diferem significativamente ao nível de $5 \%$ de probabilidade de acordo com o teste de Duncan.

(1) Após a emergência da soja.

QUADRO 9. Estatura das plantas de quatro cultivares de soja submetidos à competição de três densidades e dois periodos de ocorrência de Euphorbia heterophylla L., EEA/UFGS, Guaíba, RS, 1979/80.

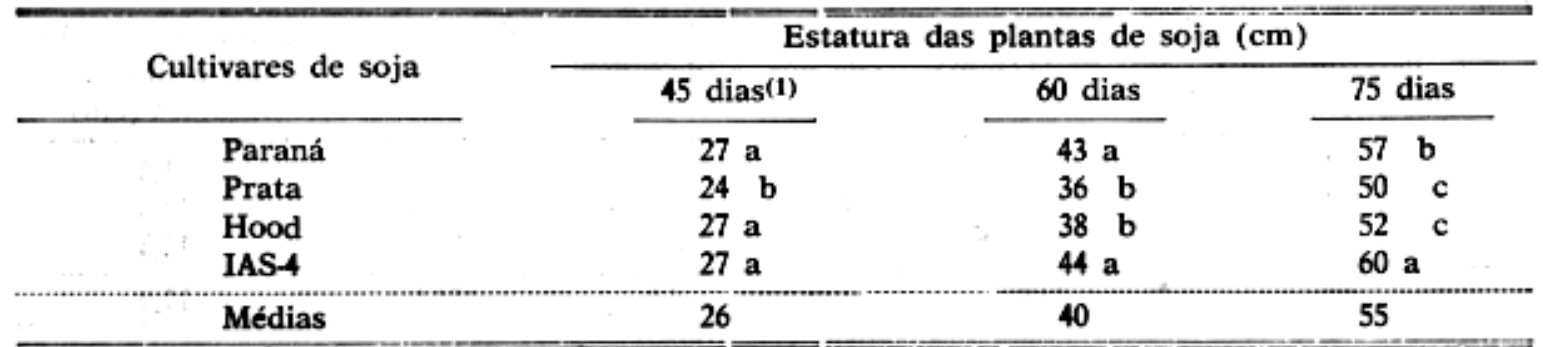

Médias comparadas no sentido horizontal, antecedidas da mesma letra, e médias comparadas no sentido vertical, seguidas da mesma letra, não diferem significativamente ao nível de $5 \%$ de probabilidade de acordo com o teste de Duncan.

(1) Após a emergência da soja.

QUADRO 10. Indices de área foliar, médias de quatro cultivares de soja submetidos à competição de três densidades e dois periodos de ocorrência de Euphorbia heterophylla L., EEA/ UFRGS, Guaíba, RS, 1979/80.

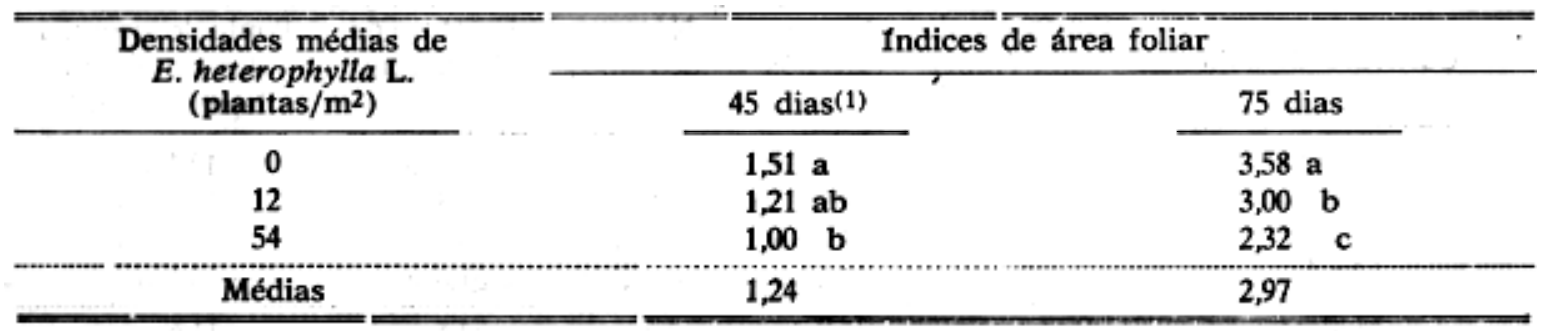

Médias comparadas no sentido horizontal, antecedidas da mesma letra, e médias comparadas no sentido vertical, seguidas da mesma letra, não diferem significativamente ao nível de $5 \%$ de probabilidade de acordo com o teste de Duncan.

(1) Após a emergência da soja. 
QUADRO 8. Indices de área foliar de quatro cultivares de soja submetidos à competição de três densidades e de dois períodos de ocorrência de Euphorbia heterophylla L., EEA/UFRGS, Guaíba, RS, 1979/80.

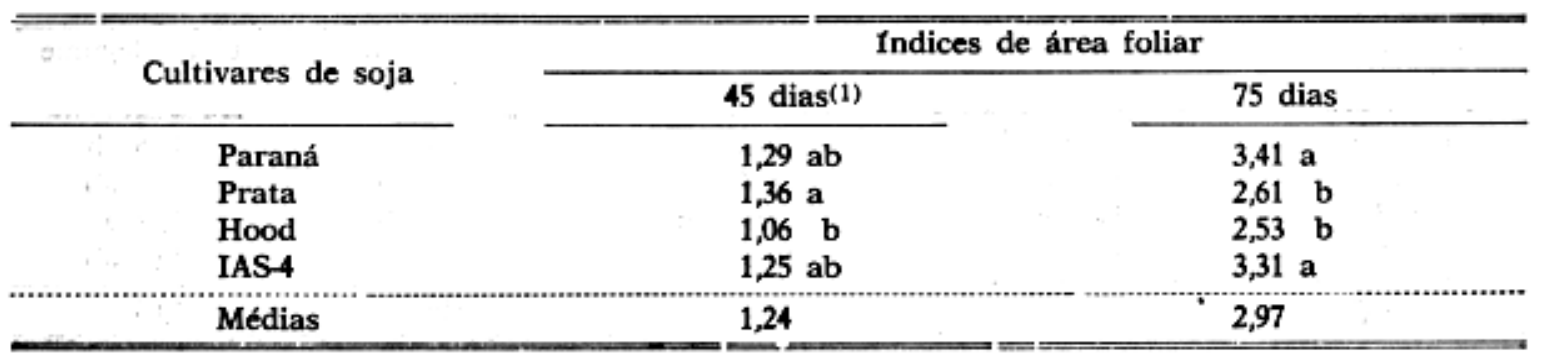

Médias comparadas no sentido horizontal, antecedidas da mesmà letra, e médias comparadas no sentido vertical, seguidas da mesma letra, não diferem significativamente ao nível de $5 \%$ de probabilidade de acordo com o teste de Duncan.

(1) Após a emergência da soja.

QUADRO 9. Estatura das plantas de quatro cultivares de soja submetidos à competição de três densidades e dois períodos de ocorrência de Euphorbia heterophylla L., EEA/UFRGS, Guaíba, RS, 1979/80.

\begin{tabular}{|c|c|c|c|c|}
\hline \multirow{2}{*}{\multicolumn{2}{|c|}{ Cultivares de soja }} & \multicolumn{3}{|c|}{ Estatura das plantas de soja $(\mathrm{cm})$} \\
\hline & & 45 dias(1) & $\frac{60 \text { dias }}{43 a}$ & 75 dias \\
\hline$\cdots$ & $\begin{array}{l}\text { Paraná } \\
\text { Prata } \\
\text { Hood } \\
\text { IAS-4 }\end{array}$ & $\begin{array}{l}27 \text { a } \\
24 \quad \text { b } \\
27 \text { a } \\
27 \text { a }\end{array}$ & $\begin{array}{l}43 \mathrm{a} \\
36 \quad \mathrm{~b} \\
38 \mathrm{~b} \\
44 \mathrm{a}\end{array}$ & $\begin{array}{ll}57 & \text { b } \\
50 & \text { c } \\
52 & \text { c } \\
60 & a\end{array}$ \\
\hline & Médias & 26 & 40 & 55 \\
\hline
\end{tabular}

Médias comparadas no sentido horizontal, antecedidas da mesma letra, e médias comparadas no sentido vertical, seguidas da mesma letra, não diferem significativamente ao nível de $5 \%$ de probabilidade de acordo com o teste de Duncan.

(1) Após a emergência da soja.

QUADRO 10. Indices de área foliar, médias de quatro cultivares de soja submetidos à competição de três densidades e dois períodos de ocorrência de Euphorbia heterophylla L., EEA/ UFRGS, Guaíba, RS, 1979/80.

\begin{tabular}{|c|c|c|}
\hline \multirow{2}{*}{$\begin{array}{l}\text { Densidades médias de } \\
\text { E. heterophylla } \mathrm{L} . \\
\text { (plantas } / \mathrm{m}^{2} \text { ) }\end{array}$} & \multicolumn{2}{|c|}{ Indices de área foliar } \\
\hline & $45 \operatorname{dias}(1)$ & 75 dias \\
\hline $\begin{array}{r}0 \\
12 \\
54\end{array}$ & $\begin{array}{l}1,51 \mathrm{a} \\
1,21 \mathrm{ab} \\
1,00 \mathrm{~b}\end{array}$ & $\begin{array}{ll}3,58 & \mathrm{a} \\
3,00 & \mathrm{~b} \\
2,32 & \mathrm{c}\end{array}$ \\
\hline Médias & 1,24 & 2,97 \\
\hline
\end{tabular}

Médias comparadas no sentido horizontal, antecedidas da mesma letra, e médias comparadas no sentido vertical, seguidas da mesma letra, não diferem significativamente ao nível de $5 \%$ de probabilidade de acordo com o teste de Duncan.

(1) Após a emergência da soja. 
QU ADRO 11. Equações de regressão entre densidades de Euphorbia heterophylla L. e rendimento de grãos de cultivares de soja, EEA/UFRGS, Guaíba, RS, 1979/80.

\begin{tabular}{|c|c|c|c|c|}
\hline Cultivares de soja(1) & Modelo linear(2) & $\mathbf{R}^{2}$ & Modelo aquático(3) & $\mathbf{R}^{2}$ \\
\hline Paraná & $Y=2569-18,01 X$ & 0,76 & $Y=2696-31,99 X+0,1453 X^{2}$ & 0,83 \\
\hline Prata & $Y=2599-17,66 \mathrm{X}$ & 0,50 & $Y=2865-54,58 X+0,4503 X^{2}$ & 0,80 \\
\hline Hood & $Y=2717-19,64 X$ & 0,74 & $Y=2867-53,71+0,4846 X^{2}$ & 0,84 \\
\hline IAS-4 & $Y=2952-19,22 X$ & 0,68 & $Y=3132-51,69 X+0,4022 X^{2}$ & 0,81 \\
\hline
\end{tabular}

(1) Competição durante um período de 115 dias

(2) $Y=a+b x$

(3) $Y=a+b x+c x^{2}$ 